Revista de la red interuniversitaria de estudios sobre las literaturas rioplatenses contemporáneas en Francia

$18 \mid 2018$

El río y la ciudad

\title{
Empatía y distancia: formas de comprender el espacio fluvial
}

\section{Graciela Silvestri}

\section{OpenEdition \\ Journals}

Edición electrónica

URL: http://journals.openedition.org/lirico/5698

DOI: 10.4000/lirico.5698

ISSN: 2262-8339

Editor

Réseau interuniversitaire d'étude des littératures contemporaines du Río de la Plata

\section{Referencia electrónica}

Graciela Silvestri, « Empatía y distancia: formas de comprender el espacio fluvial », Cuadernos LIRICO [En línea], 18 | 2018, Puesto en línea el 13 octubre 2018, consultado el 19 abril 2019. URL : http:// journals.openedition.org/lirico/5698; DOI : 10.4000/lirico.5698

Este documento fue generado automáticamente el 19 abril 2019.

\section{(c) $(1) \odot$}

Cuadernos LIRICO está distribuido bajo una Licencia Creative Commons Atribución-NoComercialSinDerivar 4.0 Internacional. 


\title{
Empatía y distancia: formas de comprender el espacio fluvial
}

\author{
Graciela Silvestri
}

\section{I}

Hace más de diez años, un conflicto en apariencia menor condujo a la Argentina y a Uruguay al borde de la ruptura de relaciones. Me refiero al que enfrentó las ciudades de Gualeguaychú y Fray Bentos, en ambas orillas del río Uruguay, en la cuenca del Plata, a raíz de la instalación de dos plantas de procesamiento de celulosa en el país oriental: una española -que retiró su proyecto- y la otra finlandesa, Orión-Botnia, que había iniciado su construcción. El conflicto escaló hasta que, en el verano de 2007, tres puentes internacionales fueron bloqueados en protesta por una multitud oganizada por diversas Ongs. Se acudió a los tribunales de La Haya: los argentinos indicando el grave impacto ambiental causado por la papelera y el incumplimiento del país vecino del tratado del río Uruguay; los uruguayos denunciando la acción de corte de rutas como una afrenta al derecho internacional. Más allá del fallo internacional -en contra de Uruguay por incumplimiento de los procedimientos de cooperación, pero a su favor para continuar la construcción de la papelera-, el enfrentamiento dejó en claro que sensibilidad ecologista y objetivos de progreso no siempre van de la mano.

La publicidad del conflicto puso en primer plano una serie de cuestiones hasta entonces poco atendidas. En principio, difundió el giro reciente de las preocupaciones ambientales: la identificación del agua como último "recurso escaso", impulsando la creación o el fortalecimiento de organizaciones civiles dedicadas especialmente al "salvataje" de los ríos. Ellas se opusieron sistemáticamente a las transformaciones técnicas que ponían en riesgo el recurso y los paisajes que con él estaban ligados -las canalizaciones y rectificaciones en función de la navegación, los aterramientos, desecamientos y drenajes, la utilización del agua como recurso energético en diques y centrales hidroeléctricas-. La campaña "ríos vivos" relacionaba la transformación del progreso con la muerte. 
Sudamérica ya constituía un caso en los foros internacionales: sus tres grandes cuencas fluviales (la del Orinoco, la del Amazonas, la del Plata), sumando esteros, pantanos y acuíferos, conforman la mayor reserva de agua potable de la Tierra. Las divisiones nacionales habían invisibilizado esta dimensión continental, y también la regional. Los ríos se habían convertido en límites "naturales" antes que en caminos de reunión. Hoy, y no sólo por la centralidad del elemento en la última década, el agua se ha convertido en protagonista ecológico que no sólo resiste materialmente la posibilidad de división sino que parece funcionar como metáfora del mundo global (espacios líquidos sin fronteras) que pone en cuestión la idea misma de territorio jurídico-político. Esta imagen, construida por el arquitecto Jorge Silvetti, nos advierte: habitamos en el agua y no en la tierra, un agua que no es llana superficie marina, sino intrincada madeja de ríos.

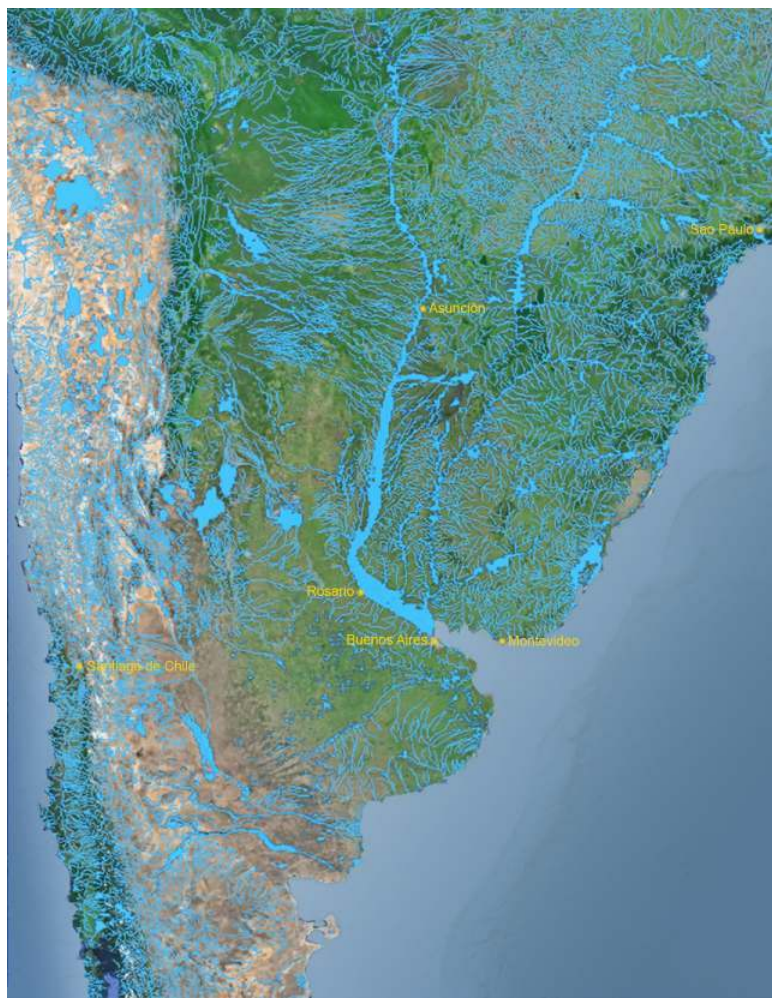

Figura $1^{1}$

A pesar de los notables cambios que la lógica del agua produjo en la consideración del espacio, un aspecto clave en el conflicto apenas fue considerado: me refiero a la percepción estética de los paisajes acuáticos. Si la ciudad de Gualeguaychú se había levantado contra las papeleras no había sido, en primera instancia, por la polución del río, sino por el impacto en los paisajes costeros que la ciudad ofrecía como destino turístico. La playa de Ñandubaysal se encuentra frente a Botnia: ¿y quién veranea admirando una fábrica? No era sólo una cuestión de vistas: el olor de la producción de papel alcanza la ciudad. Ya no creemos en miasmas, pero el olor forma parte de nuestro disfrute o desagrado ante un paisaje. Estamos hablando de percepción estética, pues, en un sentido más amplio que el puramente artístico, apelando a sentidos no simbólicos.

Ni las Ongs ni sus detractores consideraron el argumento estético como central, aun cuando éste no podía desecharse en la industria del turismo. Las apreciaciones sensibles fueron consideradas, como hubiéramos dicho en nuestra juventud, superestructurales. Ah, pensé, si sólo la fábrica hubiera atenuado su perfil moderno, presentándose como ruina 
romana, o incluso como ruina de algún viejo frigorífico desactivado, el "paisaje degradado" se hubiera convertido en celebrado paisaje cultural. Identificamos un paisaje como bello y natural, aunque esté técnicamente transformado, cuando naturaleza y artificio se encuentran en un tipo de relación que excluye la disruptiva novedad. Para que interpretemos un paisaje como paisaje natural es paradójicamente necesario que haya sido edificada una historia o, más precisamente, una memoria colectiva. Incluso la novedad puede ser domesticada y apreciada si contamos una historia.

\section{II}

En el episodio de Gualeguaychú están condensadas las preguntas de esta ponencia. La hipótesis de que la apreciación estética del paisaje fue detonante de un evento político de magnitud vuelve a colocar la vieja idea de belleza natural en primer plano. Se objetará que la palabra belleza ya no es siquiera considerada en el mundo del arte; que decir paisaje natural es un contrasentido, porque el paisaje es siempre construido por una cierta mirada. Pero la idea de que existe algo como "belleza natural" es compartida por muy diversos sectores sociales y culturales, y se mantiene firme, si hemos de creer a las imágenes difundidas por internet como evidencia de los peligros de la intervención técnica.

La apreciación estética de los paisajes fluviales posee sus particularidades. No nos enfrentamos, como en las pampas o los Andes, con las pasiones causadas por lo Sublime, aquellas que Edmond Burke definió ligadas a la experiencia sobrecogedora de la naturaleza. Se trata de paisajes menores, en los que palabras descartadas para cualificar la experiencia artística, como "agradable" o placentero, recobran su lugar -debiéramos reemplazar la ampulosa palabra belleza por gracia-. Por otro lado, estamos bien lejos del desinterés que las estéticas de la recepción subrayan en la experiencia del arte, del puro gusto sin finalidad. Su apreciación no prescinde de aspectos "útiles" (la frescura del agua mansa en las tórridas tardes de verano; el aprovechamiento culinario de la pesca del día). Tampoco prescinde de afectos y sentimientos -todo paisaje de río o arroyo en calma remite a la infancia, a la materna protección-. Estos paisajes parecen resumir un horizonte común de bienestar, paz, juventud y felicidad que se encuentra en el núcleo de la misma idea de belleza natural, por lo que no extraña que la representación del trabajo, la fábrica, deba ser excluida o presentada como pasado -las vacaciones suspenden toda obligación.

Es cierto que esta idea de universalidad de la fruición paisajística ha sido puesta en jaque desde diversas perspectivas. En principio, cuando decimos paisaje damos por supuesta una noción contemplativa, eminentemente visual, literaria y poética, diferenciada de lo que Piero Camporesi llamó "paessaggio dal basso", atendiendo a las descripciones de la geografía italiana antes de que las escenas del bel paessaggio fueran construidas como motivo pictórico ${ }^{2}$. Las prácticas de observación, así como las percepciones sensibles (táctiles, sonoras, olfativas-gustativas), aparecían en relación con la utilidad o el placer inmediato -hallar una veta mineral, un terreno cultivado, una cierta cualidad del agua, gordas mujeres o ricos quesos-. En muchos trabajos académicos de fin de siglo pasado, se propuso una oposición radical entre la percepción del habitante -al que a veces se le negó capacidad estética- y la distancia del turista/contemplador. Camporesi prueba la continuidad y relación de dos tipos de percepción estética. 
La aparente oposición entre una mirada desde abajo y otra desde arriba, la intimidad y la distancia, nos conduce a dos nociones fundamentales en la estética de los dos últimos siglos: Einfuhlung (empatía en la versión derivada de la traducción inglesa) y extrañamiento. La idea de Einfuhlung tiende a eliminar las distinciones entre hombre y mundo, animado e inanimado, fenómenos naturales o artificiales, el Uno y lo Otro, atendiendo a las resonancias de las cosas en la vida humana -en su alma o en su cuerpo, según las diferentes versiones-. Se trata de una sensibilidad panteísta, en la que emociones y afectos juegan un papel sustancial, y que, al extenderse más allá de las fronteras de la contemplación artística, remite a la experiencia -para vibrar en la misma cuerda de las cosas del mundo, es necesario sumergirse en él-. Muchos consideraron que tal perspectiva fue demolida cuando Schklovsky describió como centro de la actividad artística el procedimiento del extrañamiento (ostraniene), aunque las reservas ya eran manifiestas en la oposición de Wörringer entre abstraction y Einfuhlung ${ }^{3}$. Considerando que los hábitos cotidianos, automáticos, adormecen las sensaciones impidiendo ver el mundo con ojos nuevos, el artista debe ejercer una violencia sobre el espectador, y sobre sí mismo, para volver sensibles a las cosas -recuperarlas a través de la distancia de la razón.

La noción de empatía, sin embargo, estaba lejos de resumirse en la decadente sensibilidad de princesas y claros de luna. Fue pieza central en las elaboraciones de muchos teóricos materialistas que intentaban reunir las nuevas aproximaciones de la ciencia (especialmente, de la psicología de la percepción) con los caminos del arte. Entre ellos, August Schmarzow, quien introdujo la palabra espacio para definir la disciplina arquitectónica, interpretándolo como extensión kinética del cuerpo. Consciente de la doble condición de la fruición del espacio (inmersión en lo vivido para el usuario, distancia de la razón para el proyectista-productor), acuñó la idea de Körpergefühle (sentimientos del cuerpo), determinados doblemente por Tastregionen (regiones del tacto, ligadas a la sensibilidad directa) y Sehregionen (regiones de la vista, el "sentido más amado" de Aristóteles, porque está ligado a la distinción entre las cosas y, con ello, a la razón) ${ }^{4}$. Esta doble condición está en la base de lo que más tarde se conoció como "movimiento moderno" en arquitectura y su difícil juego entre lo alto y lo bajo; experiencia distraída y férreo control; voluntad de progreso y urgencia de regresar al estado de naïveté originelle, la del niño o del "salvaje". Empatía y extrañamiento se traman de manera indisoluble.

¿Por qué detenerse en esta aparente oposición en el caso de los paisajes fluviales? En principio, porque el motivo del agua fue uno de los más reiterados en la construcción icónica y literaria del paisaje modernista para desarmar los supuestos clásicos de la forma, ligada a la permanencia y la distinción, a la distancia, a la contemplación. Desde Turner a Monet, el camino de la sensación, de lo efímero, de lo inmediato, de los colores y brillos, se ligó a la representación del agua en sus diversos estados (niebla, lluvia, tormentas, espejos plácidos, mares y lagos). "Sumergirse" en los paisajes acuáticos implicaba sumergirse en el elemento herácliteo por excelencia, metáfora del movimiento y del tiempo; no existe perspectiva fija desde donde apreciar el agua.

Pero los diversos estados y formas del agua conducen a diversas interpretaciones. El agua del río no es el agua del mar. "The river is within us, the sea is all about us", dice Eliot ${ }^{5}$, indicando las diferencias entre la extensión global del agua marina, que en condiciones tranquilas delinea un horizonte apreciado desde una altura -la borda del barco-, y la percepción de lo cotidiano y familiar que sugiere el río. El mar condujo a interpretaciones sublimes (dinámicas y caóticas, o serenas, matemáticas, según la división kantiana); los 
ríos y arroyos, a representaciones íntimas, profundas. ¿Cómo se han interpretado los vastos ríos de nuestros paisajes rioplatenses, que muchas veces, como el mar, "hacen horizonte"?

\section{III}

Presento dos ejemplos muy conocidos para ponerlos en relación. El primero es un poema de Juan L. Ortiz:

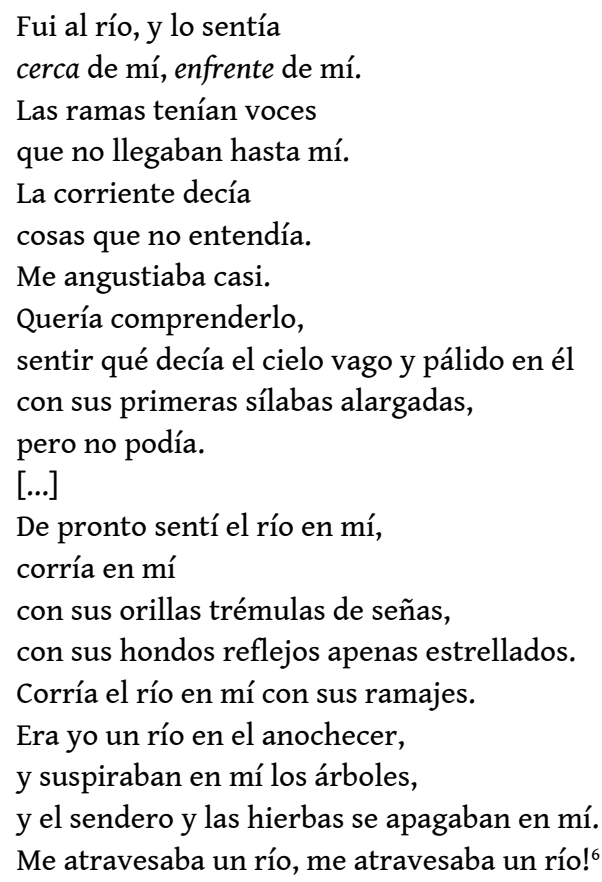

Subrayé cerca (en la definición del diccionario, objetos situados en el primer término de un cuadro); y enfrente: quien mira delante del otro, indicando jerarquía y distancia. En el último párrafo, el río se instala en el mismo cuerpo -y ya es uno con las cosas-. Se trata de una percepción empática del mundo, táctil, corpórea, latamente material. 


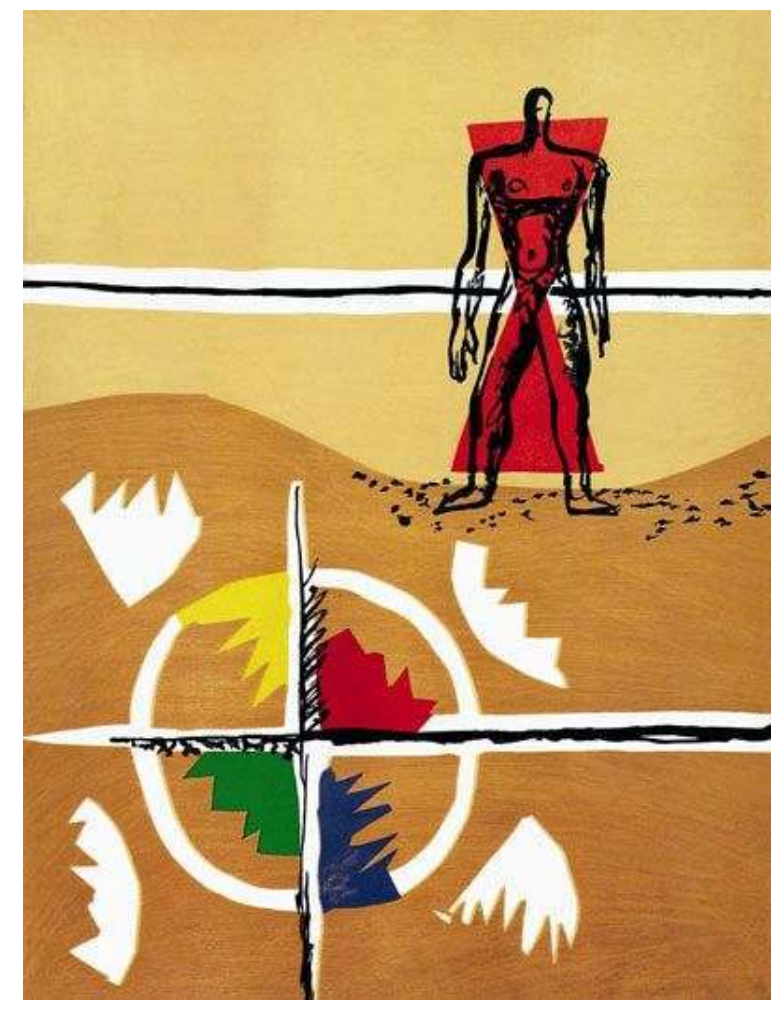

Figura $2^{7}$

El segundo ejemplo es de Le Corbusier, que ha dejado profundas huellas en las formas de encarar el plan urbano en los litorales rioplatenses. El motivo principal en El poema del ángulo recto descansa en la famosa oposición de la geografía hegeliana: tierra y mar.

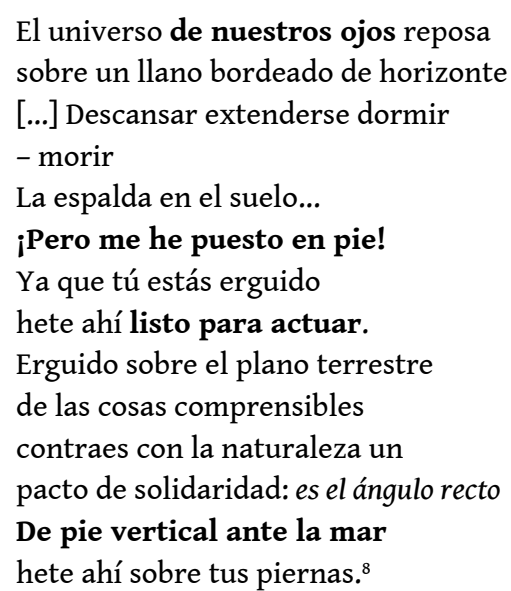

El hombre erecto se yergue sobre el "plano terrestre de las cosas comprensibles", de pie vertical ante la mar (Figura 2). Este hombre se encuentra ante las aguas, no en las aguas: necesita un plano firme para mantenerse erguido y actuar; construye una distancia y se proyecta hacia el horizonte. Olvida su radicación originaria y expande su dominio.

Le Corbusier ya había sugerido esta disyuntiva en La cabeza de Apolo y Medusa (1942). Un eje la divide: del lado izquierdo, la horrible cara de Medusa, coronada de serpientes -el lado inquietante del agua-; del derecho, el Sol -Apolo, cuya clara geometría es suavizada por el trazo a mano alzada- (Figura 3). El camino que sigue a Medusa nos devuelve al barro original; el guiado por el ojo de Apolo, nos orienta hacia la claridad de la razón. Otra ilustración del poema -la de una mujer acostada, ligada a los ríos (la acompaña un pez), 
soñando con serpientes- parece matizar esta tajante oposición (Figura 4). La ilustración aparece asociada con "la ley del meandro", el aforismo que encierra la ley acuática, femenina (el agua es siempre femenina), lunar y terrible de la vida, y más precisamente, la ley de toda creación estética. Le Corbusier venía imaginando este paralelo desde que realizó su segundo viaje en avión, desde Buenos Aires hasta Asunción, observando el Paraná: los bucles del río buscando su cauce, corriendo hacia izquierda y derecha de una orilla a otra, los atasques y tropiezos, los callejones sin salida y su triunfo final representan el proceso creativo. De allí se parte inevitablemente ("Entre protuberancias y en fisuras/ deslizándose sobre las durezas y hundiéndose en las blanduras/ el que se arrastra el que va como la lombriz/ el que avanza sinuosamente el que repta han esbozado la propulsión primera. Los gusanos y las serpientes/ los gusanos venidos del potencial de las carroñas. Los arroyos los riachuelos y los ríos hacen otro tanto"). Pero cuando lo inextricable ("lo insensato") cierra el camino, "la vida" exigirá paso: "Ella cortará el meandro/ horadará sus bucles soldándolos allá precisamente donde un curso desvergonzado les había hecho tocarse. ¡La corriente fluye recta de nuevo!”. En ambiguo paralelo, Le Corbusier termina esta parte del poema asociándola a los caminos del pensamiento creativo: "La ley del meandro actúa en el pensamiento y la empresa de los hombres fomenta allí avatares renacientes Pero la trayectoria surgida del espíritu es proyectada por los clarividentes más allá de la confusión". 9

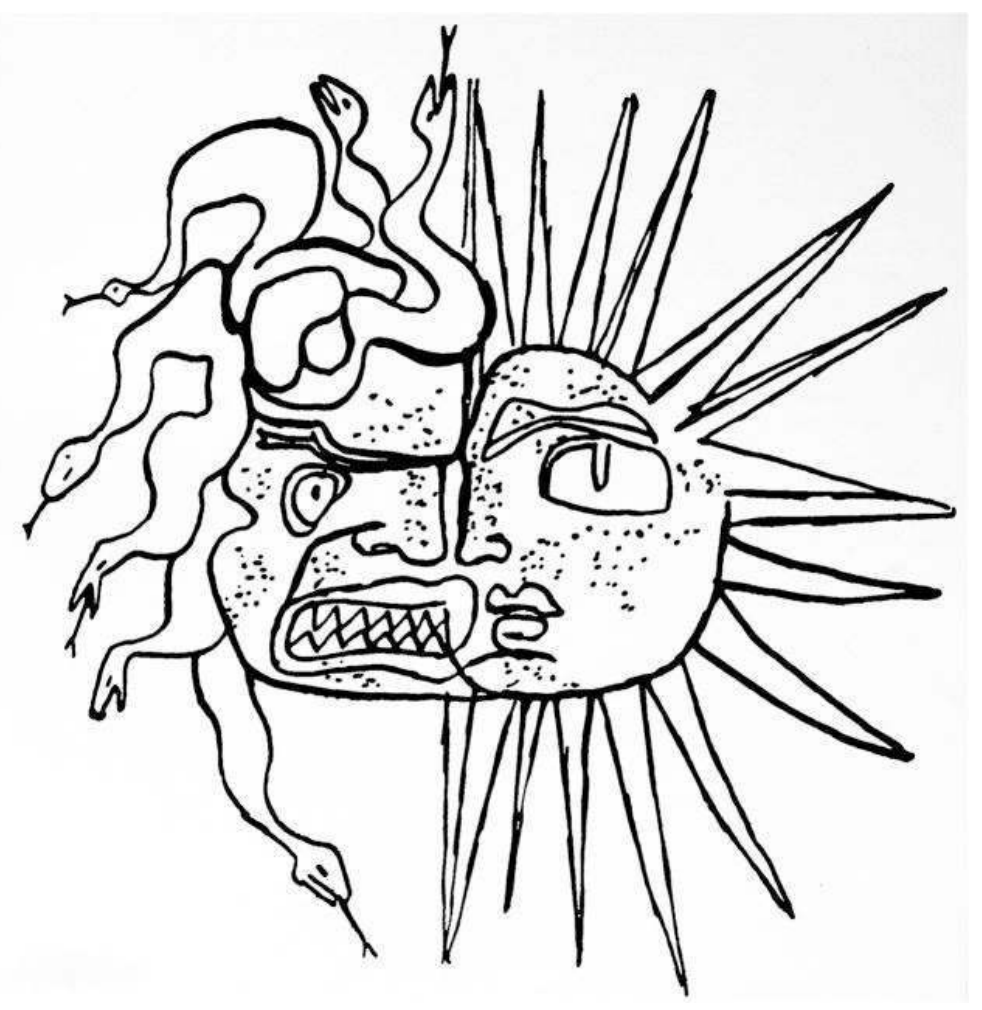

Figura $3^{10}$

Se entiende por qué Le Corbusier elige a Medusa-agua, a la mujer, a las serpientes y a los gusanos para representar el caos original que, sin embargo, es inescindible de la vida. La arquitectura nunca fue proclive a tratar con el agua. De los diez libros de Vitruvio, sólo uno se refiere al agua, aunque los romanos fueron maestros en la ingeniería de los fluidos. El peso de la arquitectura parece colocarla en el extremo opuesto de la liquidez. Los tratados aconsejan la cercanía de una fuente de agua, pero ella se debe encontrar a cierta distancia: el agua, siempre dispuesta a mezclarse con todo, se expande por los intersticios 
de los elementos inertes, disolviéndolos sin prisa y sin pausa, atentando contra la firmeza. La firmeza no implica sólo un problema técnico: en el mundo clásico, la arquitectura (que construye la ciudad) debe permanecer como testimonio material tan elocuente como las palabras y las imágenes para asegurar una memoria material que subsista a través de las generaciones. De allí la obsesión por crear formas que perduren, reconocibles como producto de manos humanas. Y el reconocimiento de que algo ha sido hecho por humanos descansa, todavía hoy, en la identificación de una geometría -cualquier geometría: euclideana, topológica o paramétrica-, es decir, de un orden que se hace visible con los ojos del cuerpo y del espíritu. La geometría estructura la concordancia entre objetos y materiales disímiles -y es en esta concordancia, según el dictum clasicista, donde se encuentra la armonía, la belleza. Por esto, la ruina que, a merced del tiempo, ha perdido "coherencia" humana, se asocia a la Naturaleza.

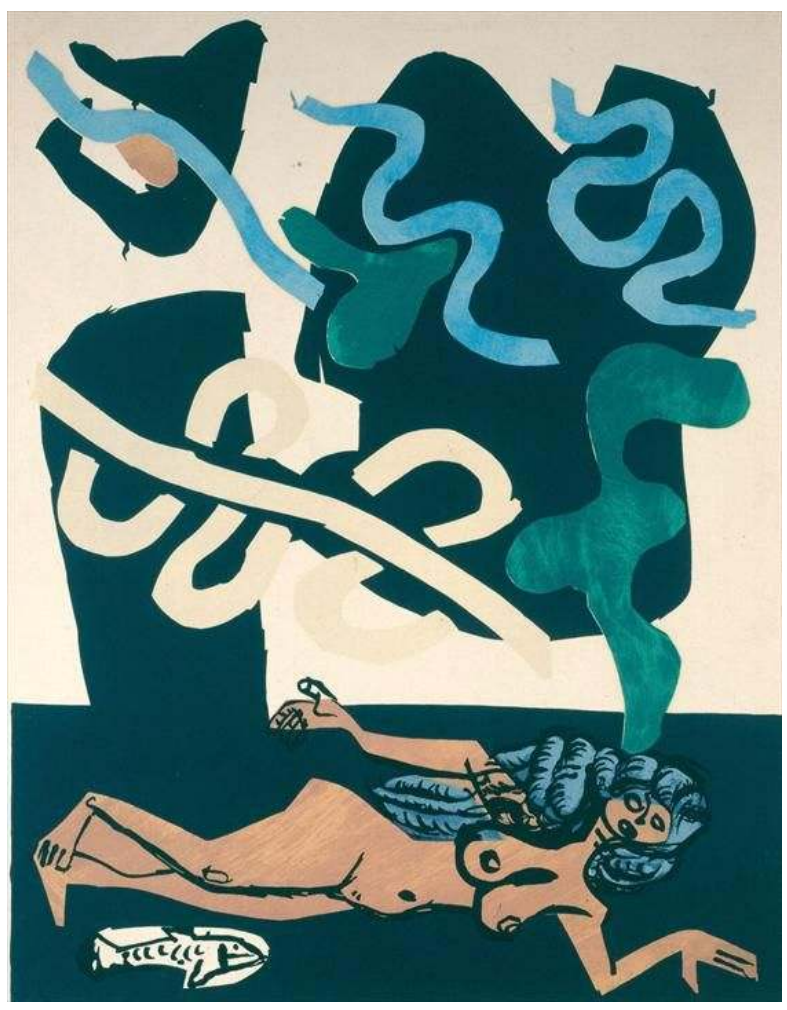

Figura $4^{11}$

Le Corbusier jugará toda su vida con estas dos almas -la femenina medusa y el límpido y masculino espíritu solar-. De hecho, en su viaje americano ya plantea, para las costas de Río de Janeiro, una megamáquina serpentina que luego volverá a utilizar en su plan para Argel. Pero el paisaje de la capital del Plata, Buenos Aires, no admite ambigüedades. Este es el famoso croquis del Río de la Plata que realizó en su viaje de 1929. En el texto que acompaña la imagen, el Río de la Plata es comparado con un mar rosado ${ }^{12}$ (Figura 5). Hacia él debe abrirse la ciudad que todavía permanece cerrada a las sugerencias fluviales. Aprovechando la naturaleza ambigua del Plata, tierra y agua a la vez, el arquitecto imagina el crecimiento de la ciudad sobre el río, una sugerencia clave hasta hoy. En la imagen, el llano bajo un cielo bordeado de horizonte es sublime. Se trata de un Sublime extensivo, matemático -aprehensible por la razón-. La interpretación más precisa del río lecorbusierano, imaginado como un mar, es la de Amancio Williams: en esta imagen vemos la reconstrucción, realizada por Claudio Veckstein, del monumento que Williams 
proyectó en memoria de su padre en 1962, dos sutiles bóvedas cáscaras, cuadrangulares, elevadas sobre finos pilares de $11 \mathrm{~m}$ de altura. El perfecto y armónico perfil de la obra humana contrasta con la distendida inmensidad (Figura 6). Tanto en el caso de Le Corbusier como en el de Williams, este paisaje implica distancia: siempre se percibe enmarcado en una lejanía, como proyectándose hacia el futuro.

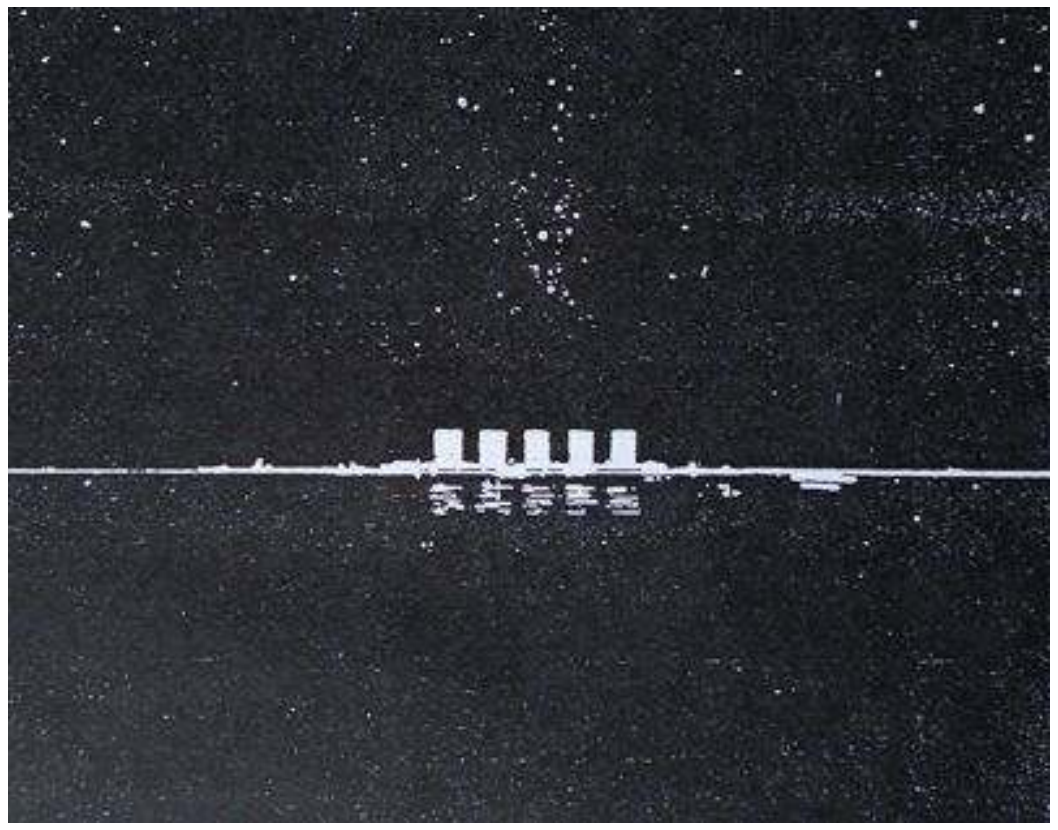

Figura $5^{13}$

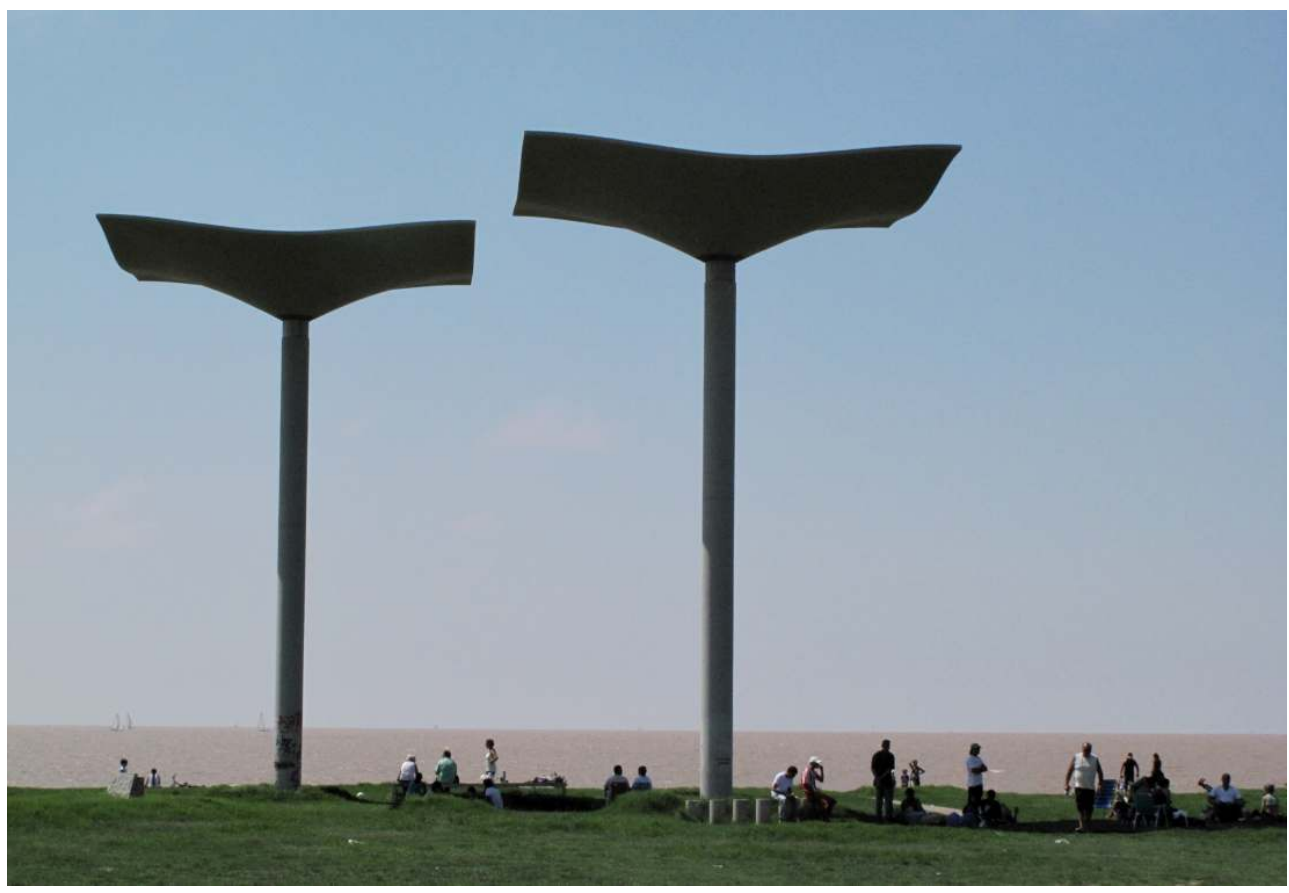

Figura $66^{14}$

El estuario del Plata encontró sus metáforas y su arquitectura en esta huella -décadas después, los planes derivados del potente croquis volverán a insistir sobre el tema de las imponentes torres sobre la costa dura, dialogando con el cielo de la cruz del sur y el "mar 
rosado"-. Otros paisajes en los que el agua era protagonista, como el de los arroyos cordobeses, realzaron en cambio su carácter íntimo apelando a variados pintoresquismos.

Pero el gran Paraná propone una interpretación más ambigua: para la mirada europea, no es río, ni arroyo, ni mar. La tradición fundacional alejaba a las ciudades de los peligros del agua -Santa Fe, inicialmente establecida sobre el río San Javier, debió mudarse por la erosión de las barrancas-; las costas informes y barrosas no presentaban el atractivo de los arroyos y en los bajos, precisamente, crecieron las poblaciones informales, las casas de mala fama -en Buenos Aires, el tango-. En las ciudades puerto de importancia, como Buenos Aires y Rosario, una franja de instalaciones de almacenaje y circulación alejó aún más a la ciudad del río. Donde era posible ver el río sin obstáculos, ya avanzado el siglo XIX y sobre todo en el siglo XX, se construyeron paseos costaneros (uno de los más hermosos, el de Corrientes, abrazada por el río que vira en este punto). La costa debía ser dura y fija para evitar la erosión del río. Hacia la década de 1980, el tema de las ciudades fluviales costeras que habían "negado el río" se articuló con la obsolescencia de la infraestructura industrial-portuaria, y en algunos casos, del que Rosario es el ejemplo más conocido, el centro de la ciudad se renovó con un paseo costero que fue ampliándose durante las últimas décadas. Se inició con la refuncionalización de los viejos almacenes y talleres portuarios, convertido en el centro Cultural Parque España. Allí, en lo alto de una gran escalinata, el arquitecto español Oriol Bohigas colocó dos grandes columnas dóricas, aludiendo a las puertas de la tierra a la que el Paraná conduce -el camino de los conquistadores, la espada recta que fija el centro de la cruz fundacional- (Figura 7). Le Corbusier jamás hubiera puesto columnas dóricas (estamos, en 1981, en pleno "posmodernismo"), pero el gesto no es distinto al imaginado para Buenos Aires: las enormes, rectas columnas dominando el inmenso y horizontal río. En 2005, parte de la costanera -hierro y cemento- colapsó dentro del Paraná: la potencia del río horada incluso los más firmes materiales. Horada también los sueños de permanencia que la arquitectura hizo suyos.

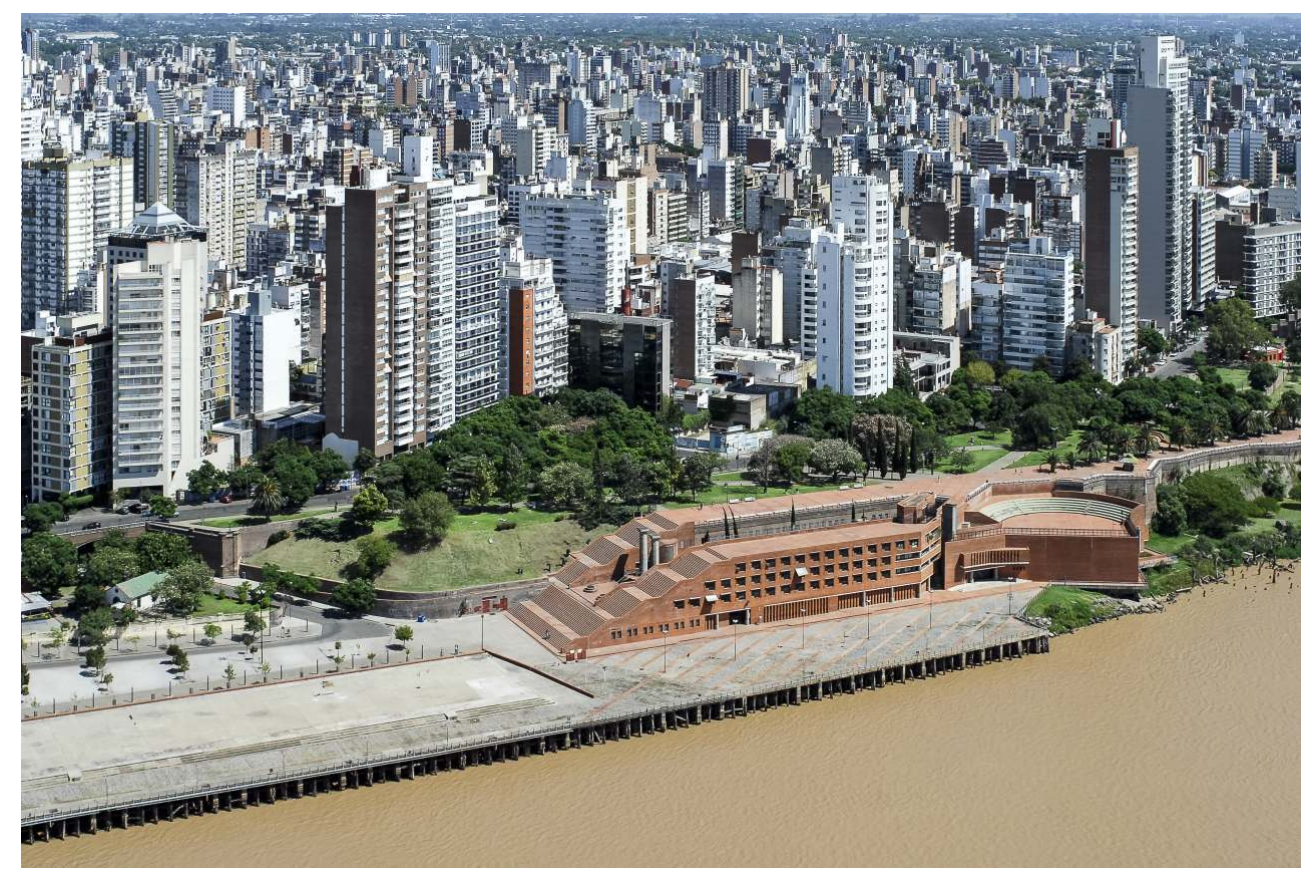

Figura $7^{15}$ 
El geógrafo Eliseo Reclus comentó la pregnancia de los pequeños ríos y arroyos de la Hélade, la infancia normal de la civilización, con los inmensos ríos americanos: "los poetas griegos supieron reconocer lo que su patria debía a esos débiles cursos de agua, que un salvaje de América ni siquiera se dignaría a mirar. El aborigen del Nuevo Mundo desprecia el arroyo porque ve correr en su terrible majestad ríos como el Madeira, el Tapajoz o el Amazonas, pero no comprende lo suficiente esas enormes masas de agua para celebrar su poder: al contemplarlas, queda sumido en una especie de estupor" ${ }^{16}$.

La inmensidad y violencia de los ríos sudamericanos parecían rechazar la misma posibilidad de civilización, de espíritu, de Estado; muchos viajeros acordaron, parafraseando a Hegel, que "el hombre en estas zonas se mantiene harto embotado, la naturaleza lo deprime, no puede separarse de ella" ${ }^{17}$. Ni pathos romántico, ni distancia racional: embotamiento, estupor. Esta relación entre geografía e historia tuvo una importancia central en la percepción de Sudamérica, dividiendo tierras bajas y andinas. Los valles de las tierras altas habrían asistido al desarrollo de una civilización: se trata de un paisaje orográfico, trabajado, arquitecturizado. Allí los ríos son profundos, transparentes; la tierra, firme. En la región de los grandes ríos, en cambio, todo se mezcla, borrando las huellas sin dejar memoria -investigaciones recientes en las áreas bajas sudamericanas han hallado rastros de enormes asentamientos, sólo visibles después del duro desmonte de la selva. Las costas urbanizadas, abiertas al mundo -al mar, al movimiento de personas, figuraciones e ideas-, luchan permanentemente para estabilizarse (en la ciudad de La Plata, capital de la provincia de Buenos Aires, trazada a nuevo en 1880, los "pequeños" afluentes del Plata que, entubados, pasaban bajo su trama, la anegaron totalmente en abril de 2013 causando más de un centenar de muertes). La arquitectura trata también de encontrar su lenguaje para el río que no es límpido y llano mar; el río que no es sólo agua sino también camalotes, enramadas, tierra; el río que es clave para la fecundidad de la tierra, para el comercio, para la comunicación y que al mismo tiempo amenaza con inesperadas destrucciones.

No extraña que las ciudades fluviales hayan tardado tanto en reconocer la "belleza natural" de su paisaje. No me refiero a la literatura y las artes visuales, que hicieron desde temprano del río un tema: pueden sumergirse empáticamente en él porque la distancia que preserva la vida ya está puesta por la representación. Burke lo sabía bien: aunque la caótica potencia natural, vinculada al terror y la muerte, resultan una fuente de lo sublime, causando emociones más fuertes que las del puro placer, "when dangers or pain press too nearly, they are incapable of giving any delight" ${ }^{18}$. Acaso era este el estupor que el propio Reclus sentía (no, necesariamente, los nativos).

Y acaso esta es la contradicción irresoluble para arquitectos-urbanistas, que persiguen aún el ideal de concordancia armónica entre necesidad y belleza. Aunque la arquitectura se plantea en estrecho diálogo con las artes y la literatura, y aunque sus planos representan (el futuro), una vez realizados materialmente ya no suponen ninguna distancia: aún las más poéticas figuraciones de la arquitectura, como los croquis de Le Corbusier, serán vividas si son construidas. Por esto, la arquitectura pretende controlar, dar forma. Por esto, el río de los planes tiene que ser controlado, utilizado y transformado para que la vida en la ciudad sea estable. 
Recordemos que las Ongs de Gualeguaychú y de Misiones relacionaban las operaciones técnicas con la muerte del río, el agua libre con la vida. Sin embargo, a pesar de nuestra empatía con el agua "natural", no podemos aceptar el corolario más sencillo de este retorno al origen: la muerte. La vinculación entre agua y muerte ya había sido indicada por Gastón Bachelard en El agua y los sueños (1941): "La muerte cotidiana es la muerte del agua. El agua corre siempre, el agua cae siempre, siempre concluye en la muerte horizontal. [...] la muerte del agua es más soñadora que la muerte de la tierra: la pena del agua es infinita" ${ }^{19}$.

La muerte es horizontal -recordemos la vertical del hombre erguido, dispuesto a la acción, en el poema lecorbusierano-. Pero esta doble orientación espacial es matizada en el poema por otra línea, similar a las trazas que los ríos dejan en su pasaje, la línea serpentina . Agua y serpiente, en efecto, se encuentran en estrecha, mítica relación, como queda claro en la cabeza de Medusa, en el potencial de los gusanos y carroñas, en el desvío sinuoso del cauce, sin dirección hasta que encuentra la recta.

Esta asociación clásica me permite introducir el último ejemplo, el hermoso y terrible cuento que todos hemos leído de chicos, El regreso de Anaconda, del uruguayo Horacio Quiroga ${ }^{20}$. El "proyecto" de Anaconda, que ya ha viajado -como los pueblos tupi-guaranídesde el corazón del Amazonas, es el de edificar con la ayuda de las inundaciones una barricada de islas de tierra, ramas, camalotes, que impida el paso de los hombres obstaculizando el paso de los barcos. Anaconda viaja en un embalsado, en compañía de un hombre agonizante, y van sucediéndose los distintos paisajes observados literalmente "desde abajo" (más debajo de lo que pedía Camporesi): desde la posición horizontal de los ojos de la víbora, brindando sus olores, sus matices coloridos, su vida microscópica. Resulta imposible detenerse en una sola escena: este río -el Paraná- condensa todos los ríos, todos los paisajes, desde las fermentaciones del agua selvática hasta la frescura que anuncia el estuario del Plata. Esta es la única narración que aborda la cuenca del Plata en toda su dimensión acuática y regional; es la que llevó más lejos el doble procedimiento de empatía y extrañamiento -mirando desde los ojos animales, el narrador que es obviamente humano se aleja de sí mismo y se acerca a la indistinción original.

El proyecto de Anaconda está destinado al fracaso. Puede interpretarse, sin duda, como las dificultades de quienes pretenden dominar el río, de utilizar su fuerza, ya sea para construir barricadas naturales o fronteras artificiales $-\mathrm{o}$, para el caso, diques $\mathrm{y}$ rectificaciones-. Anaconda muere asesinada por los hombres desde un vapor -la Técnica parece vencedora-, pero ya ha puesto sus huevos al calor del cuerpo muerto del mensú (el semiesclavo trabajador rural en las plantaciones), perpetuando el ciclo natural.

Sólo la literatura o el arte pueden procesar esta mezcla terrible, indistinta y barrosa del gran río -no del riente arroyo-. El río es el suelo oscuro de nuestra humanidad -la muerte y la vida emergen en él de manera inescindible-. Las Ongs ambientalistas no pueden menos que insistir en el carácter vital del agua materna, mientras arquitectos y legisladores, en estrecha alianza, conjuran contra la muerte con una espada recta y vertical. Pero hombre y serpiente están destinados no a vivir, sino a morir juntos, entretejidos en el embalsado de camalotes, ramas, barro y espuma. 


\section{NOTAS}

1. Jorge Silvetti y Daniel Gutiérrez, Territorio acuático. Superposición de la red hidrográfica intervenida sobre una imagen landsat.

2. Piero Camporesi, Le belle contrade. Nascita del paesaggio italiano, Milan, Garzanti, 1992.

3. A mi juicio, el planteo más acabado sobre el tema se encuentra en el artículo de Carlo Ginzburg, "Straniamento. Preistoria di un procedimento literario", Ochiachi di legno. Nove reflessioni sulla distanza, Milano, Feltrinelli, 1998, p. 15 y sig.

4. August Schmarzow, Das Wesen der architektonischen Schöpfung. Leipzig, Hiersemann, 1894. Traducción al inglés en Harry Francis Mallgrave y Eleftherios Ikonomou (eds.), Empathy, Form, and Space: Problems in German Aesthetics, 1873-1893, Santa Monica, CA, Getty Center for the History of Art and the Humanities, 1994.

5. T. S. Eliot, “The dry savages" (1941), Four Quartets, New York, Houghton Mifflin Hartcout Publishing Co., 1971.

6. Juan L. Ortiz, "Fui al río", El ángel inclinado (1937), en Obra completa, Santa Fe, Universidad Nacional del Litoral, 1996, p. 229.

7. Le Corbusier, "Hombre erecto", Le poeme de l'angle droit, éditions Teriade, Paris, 1955.

8. Le Corbusier, El poema del ángulo recto (1947-1955), Madrid, Editorial Círculo de Bellas Artes, 2006.

9. Ibidem.

10. Le Corbusier y Francois de Pierrefeu, Cabeza de Apolo y Medusa, de La Maison des Hommes, 1942.

11. Le Corbusier, "Mujer acostada", Le poeme de l'angle droit, editions Teriade, Paris, 1955.

12. Le Corbusier, Précisions sur un état présent de l'architecture et de l'urbanisme, París, Éditions Crès, collection de "L'Esprit Nouveau", 1930.

13. Le Corbusier, "Proyecto para Buenos Aires", Précisions sur un état présent de l'architecture et de l'urbanisme, Colección L'esprit nouveau, Paris, 1930.

14. Claudio Veckstein, "Monumento al fin del milenio" (2000), reconstrucción del originalmente diseñado por Amancio Williams en honor de su padre, en 1962. Foto del autor.

15. Oriol Bohigas, Parque de España, Rosario, foto Alejandro Lamas y Víctor Salcedo, 2017.

16. Élisée Reclus, Historia de un arroyo, Palma de Mallorca, Editorial José Olañeta, 2008, p. 51.

17. G.W.F. Hegel, "El nuevo mundo", Lecciones de filosofía de la historia universal, Madrid, Revista de Occidente, 1974.

18. Edmund Burke, A philosophical enquiry into the origins of our ideas of the Sublime and Beautiful, Oxford, Oxford University Press, 1998, p. 36.

19. Gaston Bachelard, L'eau et les rêves. Essai sur l'imagination de la matière (1942), Paris, Librairie José Corti, 1998. Traducción castellana: El agua y los sueños, México, Fondo de Cultura económica, 2005, p. 15.

20. Horacio Quiroga, Anaconda y El regreso de Anaconda, Buenos Aires, Ediciones Menos Cuarto, 2009. 


\section{RESÚMENES}

La instalación de dos fabricas de celulosa en Uruguay desencadenó un conflicto que, en 2007, vio como tres puentes internacionales fueron bloqueados en protesta por una multitud organizada por diversas Ongs. La publicidad del conflicto difundió el cambio de paradigma con respecto a las preocupaciones ambientales. Sin embargo un aspecto clave en el conflicto apenas fue considerado: la percepción estética de los paisajes acuáticos. La hipótesis de este trabajo es que la apreciación estética del paisaje fue detonante de un evento político de magnitud que emplaza de nuevo la belleza natural en primer plano.

L'installation de deux usines de cellulose en Uruguay a déclenché un conflit qui, en 2007, a débouché sur le blocage de trois ponts internationaux par une multitude de manifestants organisée sous la direction de plusieurs ONG. Le changement de paradigme par rapport aux questions environnementales a été diffusé par la publicité du conflit. Cependant, un aspect clé au sein du conflit n'a pas été tenu en compte: la perception esthétique de paysages aquatiques. L'hypothèse de ce travail propose la considération de l'appréciation esthétique du paysage comme un déclencheur d'un grand évènement politique qui place à nouveau la beauté naturelle au premier plan.

The installation of two cellulose factories in Uruguay triggered a clash in 2007, the which one caused the blockade of three international bridges in a protest by a crowd organized by several NGOs. The publicity of the conflict spread the change in the paradigm about the environmental concerns. Nevertheless, a key aspect in the clash barely considered was the aesthetic perception of the aquatic landscapes. The aesthetic assessment of the landscape as trigger of a significant political event that place the natural beauty at the forefront is the hypothesis of this work.

\section{ÍNDICE}

Mots-clés: projet Anaconda, Gualeguaychú, Fray Bentos, bassin du fleuve de la Plata

Palabras claves: proyecto Anaconda, Gualeguaychú, Fray Bentos, cuenca del Plata

Keywords: Anaconda project, Gualeguaychú, Fray Bentos, The Plata river basin

\section{AUTOR}

\section{GRACIELA SILVESTRI}

Universidad Nacional de La Plata, CONICET

gracisilvestri@gmail.com 